\title{
Analisis Pengendalian Intern Terhadap Piutang Usaha untuk Meminimalkan Piutang tak Tertagih (Studi Kasus Pada PT. Warna Agung Surabaya)
}

* Tania Azizah, Siti Rosyafah, Masyhad

Program Studi Akuntasi Fakultas Ekonomi dan Bisnis

Universitas Bhayangkara Surabaya, Indonesia

DOI: $10.46821 /$ ekobis.v1i2.34

\begin{abstract}
ABSTRAK
Penelitian ini membahas tentang analisis sistem pengendalian internal piutang usaha untuk meminimalkan piutang tak tertagih studi kasus pada PT. Warna Agung Surabaya. Tujuan penelitian ini adalah untuk mengetahui dan menganalisa pengendalian intern terhadap piutang usaha untuk meminimalkan piutang tak tertagih pada PT. Warna Agung Surabaya. Data yang tersediaakan diproses dan disajikan dalam metode penelitian deskriptif kualitatif. Data yang dikumpulkan di lapangan akan dijelaskan dalam bentuk tabel, sedangkan proses implementasi dan analisis akan dijelaskan dengan cara membandingkan data aktual dengan teori yang ada. Hasil dari penelitian ini adalah jumlah piutang tak tertagih atas data penjualan untuk periode 2019 yang dilakukan oleh PT. Warna Agung Surabaya dapat disimpulkan cukup baik dikarenakan untuk besarnya pas due lebih dari 30 hari meskipun mendekati angka 40\% dari standar yang diberikan perusahaan, dan pas due lebih dari 120 hari masih sesuai dengan standar dan ketentuan piutang tak tertagih yang ditetapkan oleh perusahaan. Kesimpulan dari penelitain ini adalah sistem pengendalian intern yang dilakukan perusahaan sudah cukup baik ada beberapa cara yang dilakukan perusahaan yang masih belum optimal yaitu salah satunya yang hanya menerapkan Capacity dan Character saja tidak menerapkan konsep pemberian kredit seutuhnya.
\end{abstract}

Kata kunci : Piutang Usaha, Jatuh Tempo, Piutang tak Tertagih, Sistem Pengendalian Intern.

Analysis of Internal Account Payable for Minimizing Bad Debt (Case Studies in

PT. Warna Agung Surabaya)

\begin{abstract}
This study aims to discuss about the analysis of internal account payable system for minimizing bad debt case studies in PT. Warna Agung Surabaya. The purposes of this research for knowing and analysis the internal control towards account receivable for minimizing bad debts in PT Warna Agung Surabaya. The available data will be processed and presented in qualitative descriptive research methods. Data collected in the field will be explained in the form of table, whereas the implementation process and the analysis will be explained by comparing the actual data with existing theory. The result of this research is bad debts amount for sales data in 2019 period that did by PT. Warna Agung Surabaya well enough for the amount of pas due more than 30 days although it's close to $40 \%$ from the company had established and pas due more than 120 days, it still suitable with the standard and certitude of bad debs that provided by the company. The inference of this study was the company's internal control was adequate, there are some ways that do by the company is still not optimal which is the one that only applies capacity and character, the company did not adjust the concept of giving full credit.
\end{abstract}

Keywords : Account Payable, Mature, Bad Debs, The Intern Control System. 
Vol. 1 No. 22020

\section{PENDAHULUAN}

Perkembangan dunia usaha dan persaingan bisnis yang semakin kompetitif seiring perkembangan ekonomi dan juga teknologi masa kini menuntut suatu perusahaan untuk selalu melakukan inovasi dari berbagai segmen salah satunya dalam sistem pembayarannya. Di Indonesia terdapat banyak perusahaan dengan berbagai sistem pembayarannya untuk melancarkan penjualan perusahaan tersebut, pembayaran dengan cara kontan ataupun piutang. Menurut Hery (2013:159) mendefinisikan pengendalian intern sebagai berikut:

"Pengendalian intern adalah seperangkat kebijakan dan prosedur untukmelindungi aset atau kekayaan perusahaan dari segala bentuk tindakanpenyalahgunaan, menjamin tersedianya informasi akuntansi perusahaan akurat, serta memastikan bahwa semua ketentuan (peraturan) hukum atau undang-undang serta kebijakan manajemen telah dipatuhi atau dijalankan sebagaimana mestinya oleh seluruh karyawan perusahaan".

Terdapat referensi penelitian terdahulu untuk menyusun penelitian ini seperti yang telah dilakukan oleh Efriliana (2019) dalam jurnal ini melakukan penelitian tentang Pengendalian Intern Piutang Untuk Meminimalkan Piutang Tak Tertagih KP-RI Jaya Dinas P dan K Kabupaten Simalungun. Arya, Jullie dan Jessy (2016) penulis melakukan penelitian tentang Analisis Efektivitas Sistem Pengendalian Internal Piutang dan Kerugian Piutang Tak Tertagih Pada PT. Surya Wenang Indah Manado.

Piutang merupakan pos yang penting bagi perusahaan karena merupakan aktiva lancer yang likuid dan selalu cepat perputarannya, itu berarti piutang akan menjadi kas ketika telah dilakukan pembayaran oleh pelanggan.

PT. Warna Agung adalah perusahaan manufaktur produsen cat di Indonesia yang didirikan pada tahun 1960 oleh Bapak Beny Mulyono, sejak didirikan hingga saat ini PT. Warna Agung tetap menjadi perusahaan yang sepenuhnya dimiliki dan dikelola oleh keluarga dengan motto yang diusung adalah fokus pada kepuasan pelanggan. PT. Warna Agung terdapat 11 cabang di seluruh Indonesia, dan peneliti saat ini melakukan penelitian pada cabang Surabaya, yang juga mengcover distribusi seluruh Jawa Timur, Bali, NTB dan NTT. Untuk memperluas penjualan perusahaan ini menerapkan sistem pembayaran secara tunai dan juga kredit untuk memudahkan pelanggan, tetapi dengan berbagai syarat dan ketentuan berlaku dalam setiap proses penjualannya untuk melakukan pengendalian dan juga meminimalisir terjadinya kerugian dan resiko atas piutang tak tertagih yang dapat merugikan perusahaan terutama pada piutang usaha yang diberikan kepada pelanggan, karena piutang merupakan komponen penting dalam modal kerja dan memiliki unsur penting dalam laporan keuangan yang mempunyai pengaruh besar bagi perusahaan. Dalam proses penagihannya ada beberapa masalah terhadap piutang tak tertagih dikarenakan toko/konsumen yang melakukan pembelian mengalami chaos atau bangkrut sehingga dilakukann penarikan terhadap barang-barang yang sudah di order oleh toko tersebut dan dikembalikan ke perusahaan dan untuk masalah pembayaran mengenai piutang itu sendiri akan dilaporkan ke kantor pusat sembari menunggu kebijakan apa yang akan diberikan oleh kantor 
Vol. 1 No. 22020

pusat terhadap toko yang tidak bisa melakukan pembayaran. karena itu peneliti tertarik untuk melakukan penelitian terhadap piutang usaha untuk meminimalkan piutang tak tertagih dengan menggunakan metode deskriptif kualitatif.

Berdasarkan uraian yang telah dijelaskan diatas, maka peneliti memilih judul "Analisis Pengendalian Intern Terhadap Piutang Usaha Untuk Meminimalkan Piutang Tak Tertagih (Studi Kasus Pada PT. Warna Agung Surabaya)".

\section{METODE PENELITIAN}

\section{Definisi Operasional dan Pengukuran Variabel}

Pendekatan penelitian adalah proses pemikiran peneliti yang harus mencakup keseluruhan yang ada dalam penelitian agar tercapai tujuan yang akan dicapai dan manfaat dari penelitian yang dilakukan Creswell (1988), "studi kasus merupakan penelitian yang mengeksplorasisuatu sistem yang terikat atau sebuah kasus (atau bisa jadi beberapa kasus) yangterjadi selama kurun waktu tertentu melalui pengumpulan data yang mendalamdan terperinci dari berbagai sumber informasi yang dapat dipercaya kebenaranpersaksiannya.Pengumpulan informasi dalam studi kasus menurut creswell dapat dilakukan dengan melakukan wawancara pada informan, Observasilapangan langsung, serta berbagai dokumen serta laporan yang sudah adasebelumnya dan bahan materi berbentuk audiovisual”.

Tujuan dilakukannya studi kasus ini adalah untuk melakukan penelitian secara mendalam mengenai pengendalian intern terhadap piutang usaha untuk meminimalkan piutang tak tertagih, agar dapat memberikan gambaran pada subyek tersebut.

\section{Jenis dan Sumber Data}

Jenis data yang digunakan dalam penelitian ini adalah sebagai berikut: Data Kualitatif, yaitu data yang diperoleh melalui wawancara dengan mendapatkan informasi secara lisan maupun tulisan tentang meminimalkan piutang tak tertagih. Sumber data yang diperlukan dalam penelitian ini adalah sebagai berikut:

a. Data Primer yaitu data yang bersumber pada hasil observasi yang dilakukan.

b. Data Sekunder yaitu data yag bersumber dari laporan tertulis dan dokumentasi.

\section{Batasan Penelitian}

Batasan dalam penelitain ini hanya sebatas tentang penjelasan bagaimana pengendalian intern terhadap piutang usaha untuk meminimalkan piutang tak tertagih.

\section{Asumsi Penelitian}

Asumsi peneliti dalam penelitian ini adalah jika perusahaan melakukan pengendalian intern dengan baik atau sesuai dengan prosedur yang berlaku maka dapat meningkatkan laba penjualan dan bisa meminimalisir adanya kerugian piutang tak tertagih. Tetapi apabila perusahaan tidak menjalankan pengedalian intern dengan baik maka dapat menyebabkan kerugian bagi perusahaan dan bisa mengganggu perputaran keuangan perusahaan. 


\section{Unit Analisis}

Adalah satuan tertentu yang diperhitungkan sebagai subjek atau sasaran penelitian, sasaran yang dijadikan analisis atau fokus yang diteliti. Unit analisis dalam suatu penelitian dapat berupa benda, individu, kelompok, wilayah dan waktu tertentu sesuai dengan fokus penelitian. Dalam penelitian ini jika dikaitkan dengan masalah pokok penelitian maka unit analisisnya adalah non indovidu yaitu analisis pengendalian intern atas piutang usaha pada PT. Warna Agung Surabaya. Dan studi kasus yang dilakukan peneliti adalah pengendalian intern terhadap piutang usaha untuk meminimalkan piutang tak tertagih.

\section{Teknik Pengumpulan Data}

Peneliti dalam proses pengumpulan data dilapangan menggunakan metode atau teknik pengumpulan data sebagai berikut:

1. Penelitian kepustakaan (Library Research), yaitu dengan cara mempelajari buku-buku ilmiah, jurnal peneltian terdahulu, literatur dan laporan-laporan sumber bacaan yang relevan dengan penelitian ini.

2. Penelitian lapangan (Fieldwork Research), yaitu teknik pengumpulan data dengan cara melakukan pengamatan secara langsung terhadap objek yang akan diteliti dengan cara:

a. Dokumentasi yaitu cara pengumpulan data-data berupa dokumen atau informasi yang berhubungan dengan penelitian yang dilakukan, seperti dokumen profil perusahaan

b. Observasi yaitu cara pengumpulan data dengan pengamatan secara langsung terhadap objek yang akan diteliti.

3. Wawancara (Interview), yaitu peneliti melakukan wawancara kepada manager, accounting dan staff perusahaan yang berhubungan dengan piutang usaha, pengendalian piutang dan mengenai piutang tak tertagih.

\section{Teknik Analisis Data}

Teknik analisis data yang digunakan penulis adalah dengan melakukan analisa data deskriptif kualitatif dengan terlebih dahulu mengumpulkan data yang kemudian diklarifikasi, dianalisis dan juga dengan mempelajari literatur dan jurnal mengenai piutang tak tertagih yang diperoleh dari buku dan literatur yang terkait dengan penelitian yang sedang dilakukan oleh peneliti dengan cara:

a. Mempelajari teori-teori penelitian terdahulu mengenai analisis pengendalian intern atas piutang usaha untuk meminimalkan piutang tak tertagih.

b. Menganalisis teori-teori mengenai penelitian terdahulu mengenai analisis pengendalian intern atas piutang usaha untuk meminimalkann piutang tak tertagih.

c. Mengaplikasikan teori-teori penelitian dan mencari perbandingannya pada saat melakukan studi kasus di perusahaan.

\section{HASIL ANALISIS DAN PEMBAHASAN \\ Prosedur dan Penjualan Kredit}

Untuk meningkatkan omset penjualan dan menarik minat pembeli, perusahaan melakukan berbagai macam promo seperti pembelian minimal 2 dus mendapatkan 1 kaos berlaku kelipatan, pembelian cat decolith woodstain (cat kayu berbahan dasar air) yang merupakan produk baru perusahaan dengan minimal melakukan pembelian sebanyak 15 dus mendapatkan 1 set rak, dan juga ada promo dengan 
ketentuan syarat tertentu hanya untuk toko yang dikategorikan penagihannya lancar dan siklus keuangannya baik yaitu promo pareto pembelian 350 dus mendapatkan diskon Rp. $7.500+5 \%$ yaitu dengan pembayaran 6 bulan. Sedangkan diskon normal yang diberikan perusahaan harusnya hanya sebesar Rp. 5000. Pembayaran atas pembelian kredit yang telah ditentukan oleh perusahaan yaitu 30 hari, 120 hari dan yang paling lama adalah 180 hari setelah barang diterima oleh konsumen.

Berdasarkan tabel data penjualan tahun 2019 sebanyak 10,764 konsumen dengan grand total Rp. 93,960,340,145.16 dan schedule umur piutangnya dapat diketahui yaiutu, dimana per tangaal 31 Desember 2019 untuk sisa OS atau outstanding pokok hutang konsumen yaitu sebesar Rp. 28,950,829,377.46 dengan jumlah konsumen sebanyak 3,740. Dan dari tabel 4.2 diketahui bahwa pas due lebih dari 30 hari sebesar dengan jumlah konsumen sebanyak 3,740 atau 34.75\% dan untuk outstanding pokok hutang sebesar $30.81 \%$ dengan jumlah sebanyak Rp. $28,950,829,377.46$ sedangkan untuk pas due lebih dari 120 hari dengan jumlah konsumen sebanyak 1,301 atau $12.09 \%$ dan diketahui jumlah outstanding pokok hutang sebesar $11.15 \%$ dengan jumlah Rp. 10,479,114,793.59.

\section{Pengendalian Intern Yang Dilakukan Perusahaan}

a. Pada saat tim sales akan menerima orderan dari konsumen yaitu pertama yang dilakukan sebelum menerima orderan terutama untuk toko baru dengan melakukan kunjungan ke toko tersebut, meminta data atau kelengakapan dokumenn seperti KTP, KK dan juga NPWP sebagai bukti data akurat yang diberikan kepada perusahaan.

b. Pada saat penerimaan orderan admin sales harus mengajukan persetujuan kepada kepala cabang apakah toko tersebut layak atau tidak

c. Sistem pemberian diskon, tidak semua toko diberlakukan dengan diskon yang sama, misal untuk diskon atau pemberian pareto 350 dus diskonRp. $7,500+5 \%$ hanya untuk toko berskala besar dengan kondisi keuangan yang cukup baik agar dapat melakukan pembayaran tepat pada saat jatuh tempo. Untuk diskon normal Rp. 5.500 berlaku bagi semua konsumen.

d. Kelayakan suatu kredit perusahaan hanya menerapkan Capacity dan Charactersaja tidak menerapkan konsep pemberian kredit menurut kasmir (2008:285).

Tabel 1

Daftar Penjualan

\begin{tabular}{lcc}
\hline Customer Status & Count of 2019 & Sum of 2019 \\
\hline Permanent Activation & 7,024 & $65,009,510,767.70$ \\
Suspend After Permanent Activation & 1,345 & $11,421,950,778.33$ \\
Cancel Aktivation & 1,094 & $7,049,763,805.54$ \\
Termination & 1,301 & $10,479,114,793.59$ \\
Grand Total & 10,764 & $93,960,340,145.16$ \\
Rata-rata / Bulan & 897 & $7,830,028,345.43$ \\
\hline
\end{tabular}

Sumber: PT. Warna Agung Surabaya 
Vol. 1 No. 22020

\section{Sistem Pembayaran dan Penagihan}

Sistem pembayaran dan penagihan pada PT. Warna Agung Surabaya dapat dilakukan secara tunai, transfer Bank dan juga giro. Ketentuan uang tunai penagihan yang dibawa sales harus transfer ke kantor satu minggu dua kali, jadi perusahaan tidak menerima setoran uang tunai melebihi Rp. 30.000.000, sales harus melakukan setoran ke bank atas nama perusahaan untuk meminimalisir adanya kecurangan. Sedangkan untuk proses penagihan pada konsumen yang telah jatuh tempo tetapi belum melakukan proses pembayaran maka accounting, admin faktur memberitahukan sales agar melakukan follow up terhadap konsumen yang telah jatuh tempo tetapi belum melakukan pembayaran.

\section{Penanganan Piutang Tak Tertagih}

Setelah melakukan penelitian pada PT. Warna Agung Surabaya, terdapat kasus piutang tak tertagih, yaitu piutang tak tertagih dapat dikarenakan toko mengalami kondisi kebangkrutan dalam usahanya sehingga tidak mampu untuk melakukan pembayaran sesuai dengan jatuh tempo yang diberikan perusahaan, sehingga harus dilakukan penarikan atas barang yang sudah dibeli oleh toko tersebut, dan langkah selanjutnya pihak kantor cabang melakukan pelaporan kepada pusat bahwa terdapat toko yang tidak mampu untuk melakukan pembayaran atas piutangnya, kantor pusat menrima laporan tersebut setelah itu kantor cabang menunggu kebijakan kantor pusat apakah piutang tersebut dihapusakan atau tidak.

\section{SIMPULAN}

Berdasarkan hasil analisis yang telah dilakukan oleh peneliti maka dapat disimpulakan bahwa penerapan pengendalian intern terhadap piutang usaha untuk meminimalkan piutang tak tertagih di PT. Warna Agung sudah sesuai dengan ketentuan perusahaan, akan tetapi ada beberapa yang masih dilaksanakan belum optimal, hal ini tergambar pada: a. Schedule umur piutang atas data penjualan pada tahun 2019 diketahui bahwa pas due lebih dari 30 hari sebesar dengan jumlah konsumen sebanyak 3,740 atau $34.75 \%$ dan untuk outstanding pokok hutang sebesar 30.81\% dengan jumlah sebanyak Rp. 28,950,829,377.46 Miliyar yaitu masih cukup besar untuk outstanding pokok dikarenakan mendekati angka $40 \%$ dari ketetapan perusahaan. b. Sistem pengendalian intern perusahaan ada beberapa cara yang dilakukan perusahaan yang masih belum optimal yaitu salah satunya yang hanya menerapkan Capacity dan Character saja tidak menerapkan konsep pemberian kredit seutuhnya menurut teori kasmir (2008:285) yang mana hal ini dapat menambah peluang terjadinya piutang tak tertagih dikarenakan masih belum maksimal dalam sistem pengendaliannya. Proses penagihan pada PT. Warna Agung untuk piutang tak tertagih dapat diakatakan masih belum memiliki ketegasan dalam penagihannya hal ini dapat tergambar dari interpretasi sistem penagihan untuk piutang tak tertagih yang masih harus menunggu kebijakan dari pusat apakah langkah selanjutnya yang akan diambil, pimpinan cabang tidak diberikan kebijakan seutuhnya untuk mengambil kebijakannya jika terdapat toko yang tidak mampu melakukan pembayaran sesuai dengan standard dan ketentuan yang telahditerapkan maka pada akhirnya cabang akan melakukan kelonggarang pembayaran yang tidak sesuai dengan jatuh tempo sampai jangka waktu yang belum ditentukan hingga toko tersebut mampu membayar piutangnya, hal ini dapat menghambat siklus keuangan perusahaan yang dikarenakan piutang macet. 
Dari beberapa kesimpulan diatas peneliti memberikan beberapa saran yang dapat dipertimbangkan kembali untuk mengatasi masalah piutang tak tertagih: a. Dari data penjualan pada tahun 2019 diketahui bahwa pas due lebih dari 30 hari untuk outstanding pokok hutang sebesar $30.81 \%$ yang mendekati ketentuan perusahaan sebesar $40 \%$ alangkah baiknya untuk sistem penagihannya diperketat dengan aktif mengunjungi toko sebelum masa jatuh tempo yang telah disepakati kedua belah pihak karena penagihan pada dasarnya untuk memaksimalkan penagihan dan untuk meminimalkan kerugian atas piutang tak tertagih. b. Untuk sistem pengendalian piutang tak tertagih, peneliti memberikan saran dengan menerapkan konsep kasmir (2008:285) tidak hanya capacity dan character saja namun menerapkan unsur 5C, yaitu: Capacity, Capital, Collateral, Character, Condition untuk pemberian kredit dalam meminimalisasi resiko piutang tak tertagih sehingga sesuai dengan konsep kelayakan kredit. c. Sistem penagihan lebih baik jika diberlakukan kesepakatan jaminan dan penarikan barang sebelum melakukan penjualan secara kredit untuk meminamilisir adanya kerugian dikarenakan toko tidak mampu melakukan pembayaran, sehingga tidak memperlambat pembayaran yang sudah jatuh tempo.

\section{DAFTAR PUSTAKA}

Creswell, John W. 1988.Research Design: Qualitative Quantitative Approaches, Thousand Oaks Sage Pub.

Giri, Efraim Ferdinan. 2012.Akuntansi Keuangan Menengah 1. UPP STIM YKPN. Yogyakarta.

Herry.2013, Teori Akuntansi. Lembaga Fakultas Ekonomi Universitas Indonesia, Jakarta.

Hery. 2016, Akuntansi Dasar 1 dan 2. Jakarta: Grasindo.

Ikatan Akuntansi Indonesia- Kompartemen Akuntan Publik, 2001, Standar Profesional Akuntan Publik, Per 1 Januari 2001, Penerbit Salemba Empat, Jakarta Ikatan Akuntan Indonesia. 2013. PSAK 55 (Revisi 2013) : Instrumen Keuangan. Jakarta : IAI

Institut Akuntan Publik Indonesia 2011, Standar Profesional Akuntan Publik, Per 1 Maret 2011, Penerbit Salemba Empat, Jakarta.

Kieso, Donald E., Weygandt, Jerry J., AND Warfield, Tery D. 2008. Akuntansi Intermediate. Edisi 12. Jilid I. Erlangga. Jakarta.

Kasmir. 2008, Analisis Laporan Keuangan. Jakarta: PT. Raja Grafndo Persada

K.R. Subramanyam, John J.Wild, Halsey. 2005. Analisis LaporanKeuangan Edisi Delapan.Salemba Empat. Jakarta.

Mulyadi. 2016. Sistem Akuntansi. Edisi Empat. Jakarta: Salemba Empat. 


\begin{tabular}{|c|c|c|c|c|}
\hline \multicolumn{5}{|c|}{ Lampiran 1. Schedule Umur Piutang Atas Data Penjualan } \\
\hline Keterangan & AGING & $\begin{array}{c}\text { CUSTOMER } \\
\text { STATUS }\end{array}$ & $\begin{array}{l}\text { Count of } \\
2109\end{array}$ & Sum of 2019 \\
\hline & Current & Permanent & & \\
\hline & & Activation & 7,024 & $65,009,510,767.70$ \\
\hline & & Suspend After & & \\
\hline \multirow[t]{2}{*}{ Tertunggak } & $30<45$ hari & Permanent & 1,345 & $11,421,950,778.33$ \\
\hline & & Activation & & \\
\hline Tertunggak & $45<$ hari 120 & Cancel Aktivasi & 1,094 & $7,049,763,805.54$ \\
\hline \multirow[t]{3}{*}{ Piutang Macet } & hari $>180$ & Termination & 1,301 & $10,479,114,793.59$ \\
\hline & $\begin{array}{l}\text { Grand } \\
\text { Total }\end{array}$ & & 10,764 & $93,960,340,145.16$ \\
\hline & & Suspend After & & \\
\hline \multirow[t]{3}{*}{ Tertunggak } & 31-UP & Permanent & 3,740 & $28,950,829,377.46$ \\
\hline & & Activation & & \\
\hline & & & $34.75 \%$ & $30.81 \%$ \\
\hline \multirow[t]{3}{*}{ Tertunggak } & 45-UP & Cancel Aktivasi & 2,577 & $18,106,927,314.87$ \\
\hline & & & & $19,28 \%$ \\
\hline & & & $23,95 \%$ & \\
\hline \multirow[t]{2}{*}{$\begin{array}{c}\text { Piutang } \\
\text { Macet }\end{array}$} & 120-UP & Termination & 1,301 & $10,479,114,793.59$ \\
\hline & & & $12,09 \%$ & $11,15 \%$ \\
\hline
\end{tabular}

Sumber: Diolah oleh peneliti 2020 